ГУЛЯЕВ Андрей Анатольевич - кандидат философских наук, доцент Московского финансово-промышленного университета «Синергия» (109004, Россия, г. Москва, ул. Мещанская, д. 9/14 стр. 1; andrey.gulyaev1966@yandex.ru)

\title{
ОБЩЕСТВЕННЫЕ ИЗМЕНЕНИЯ ПРИ ЦИФРОВИЗАЦИИ ЭКОНОМИКИ
}

\begin{abstract}
Аннотация. Общественные изменения при цифровизации экономики имеют ярко выраженную актуальность. Экономика становится еще более цифровой, и это ускорение подстегивается пандемией. Общественные изменения при цифровизации экономики имеют положительную направленность, которая обусловлена различными причинами. Особую роль играют инновации и стартапы, которые двигают цифровую экономику. Цифровая экономика является образцом экологичности, оптимальности, рациональности, сбережения интеллектуальных, физических, трудовых, природных ресурсов. Вместе с тем цифровая экономика имеет и огромные риски. К ним мы относим хакерство, киберпреступления, кибермошенничество, а также неконтролируемое развитие технологий искусственного интеллекта. Отсутствие национального и международного контроля над развитием и использованием этих технологий может поставить под угрозу существование человечества.
\end{abstract}

Ключевые слова: цифровая экономика, информационная безопасность, искусственный интеллект, экология, занятость населения

Введение. В современном мире глобальная экономика проходит важную в своей истории стадию цифровизации, или цифрового развития. Ранее такими важнейшими стадиями были промышленная революция и появление промышленного производства, затем переход к сфере услуг и появление постиндустриального общества и экономики. Сейчас происходит переход к цифровой экономике и цифровому обществу [Дубов 2020]. Пандемия, начавшаяся в 2020 г., подстегнула цифровизацию экономики в самых разных странах. Теперь стали актуальными вопросы, как растет экономика при цифровизации, как улучшить экологию в условиях цифровизации, как сделать экономику более цифровой. Существует большой потенциал развития цифровизации экономики как будущего мирового сообщества. Одной из проблем будущего общества и цифровой экономики станет занятость населения. Занятость станет еще более конкурентной в будущем обществе, и данную проблему надо будет решать. Примером является Швейцария, в которой введен минимальный доход на каждого жителя независимо от того, работает он или нет. Такой подход к решению проблемы занятости возможен только при эффективной экономике, имеющей постоянный значительный рост при своей цифровизации. Швейцарский подход к проблеме занятости в других странах возможен в скором будущем при решении проблемы занятости населения [Anderson 2006].

Цифровая экономика вызывает дискуссии у профессионалов. Имеется ряд вопросов ко многим понятиям и определениям цифровой экономики. Применяются словосочетания, которые рядовому человеку зачастую непонятны и расплывчаты. Какие процессы происходят в цифровой экономике, и каким образом они меняют современную экономику - эти вопросы волнуют многих. Например, у специалистов происходят одинаковые процессы цифровизации (цифровой трансформации, диджитализации, индустрии 4.0), и называется данное сочетание цифровой экономикой [Vise 2008]. Цифровая экономика основывается на информационно-коммуникационных технологиях; торговля товарами и услугами в Интернете осуществляется через электронную 
торговлю. Она состоит из трех компонентов: инфраструктуры (устройства, программное обеспечение, телекоммуникации и др.), электронного бизнеса (цифровые процессы в организациях) и электронной коммерции (продажа товаров онлайн) [Давыденко 2018].

В цифровой экономике важны сферы деятельности, где ключевыми факторами выступают данные, которые представлены в цифровом виде. Большие объемы обработки и использования данных позволяют значительно повысить рациональность, качество и эффективность различных видов производства, хранения, продажи, доставки и потребления товаров и услуг по сравнению с предыдущими формами хозяйствования [Беликова 2018].

Инфраструктурный инструментарий цифровой экономики представлен огромным множеством современных информационно-коммуникативных технологий. От цифровизации экономики (создание, распределение, обмен, потребление и утилизация товаров и услуг) получают выгоду как крупные, так и мелкие компании, государство и даже отдельные люди [Семячков 2018].

Активное внедрение цифровых инструментов (цифровая трансформация, или диджитализация) в мировой экономике продолжается уже более 20 лет [Сагынбекова 2018]. У стран и компаний сформировался структурированный подход к цифровизации экономики. При разработке и реализации стратегии цифровизации экономики специфика бизнеса и законодательное регулирование стали приоритетами для большинства значительных компаний. Информационно-коммуникационные технологии как класс включают множество инструментов и наработок - от различных датчиков состояния до теорий, обосновывающих области оптимального применения той или иной архитектуры построения программного обеспечения [Борисюк 2018]. Применение различных цифровых пакетов в экономике приводит к системному разделению труда. Возникают новые профессии, уходят в прошлое вытесняемые цифровой экономикой традиционные специальности [Кудряшов 2018]. Важнейшей и определяющей технологией цифровизации экономики является цифровая платформа. В период пандемии значение цифровых платформ еще более возросло. Важным элементом современной цифровизации экономики является наличие и развитие систем информационной безопасности. Лидером в цифровизации экономики являются США [Антонопулос 2018]. К 2030 г. лидером цифровой экономики, возможно, станет Китай. Даже у лидера современной цифровой экономики США есть проблемы с информационной безопасностью, что проявилось, в частности, в 2021 г. У Китая в конце XX в. возникли проблемы с экологией из-за растущего сектора традиционной экономики. С появлением цифровой экономики ситуация с экологией в Китае стала улучшаться.

Результаты. Цифровизация экономики имеет свои особенности и показатели. К таким показателям можно отнести следующие основные индикаторы: Digital Economy and Society Index (DESI), Networked Readiness Index (NRI), Digital Evolution Index (DEI), World Digital Competitiveness (WDC) и пр.) [Vise 2018]. Одним из заметных явлений последних лет является цифровая трансформация, принципиальное изменение экономической жизни и ее структуры, цифровая виртуализация как появление оборота виртуальных услуг, товаров, капитала. Для измерения таких показателей, как развитие цифровизации экономики и степень ее цифровой виртуализации, в исследовании применяются различные композитные индексы, характеризующие цифровизацию экономических секторов человеческой деятельности.

Большой популярностью пользуются рейтинги, основанные на таких индексах, как Индекс развития информационно-коммуникационных техноло- 
гий (ICT Development Index, IDI); Индекс цифровой экономики и общества (Digital Economy and Society Index, DESI); Индекс мировой цифровой конкурентоспособности (IMD World Digital Competiveness Index, WDCI); Индекс цифровой эволюции (Digital Evolution Index, DEI); Индекс цифровизации экономики Boston Consulting Group (eIntensity); Индекс сетевой готовности (Networked Readiness Index, NRI); Индекс развития электронного правительства (The UN Global EGovernment Development Index, EGDI); Индекс электронного участия (E-Participation Index, EPART); Индекс глобального подключения (Global Connectivity Index - GCI, Huawei); Глобальный индекс инноваций (The Global Innovation Index, GII). Рейтинги различаются между собой по исходным показателям - характеристикам уровня цифровизации экономики. При анализе показателей можно выявить общность и отличия уровня готовности мировой экономики, экономики отдельных стран к цифровизации, цифровой виртуализации и глобализации [Дубов 2020].

В цифровой экономике существуют такие технологии, так облака, распределенные вычисления, большие данные и интернет-товары. Вторая по важности группа технологий состоит из блокчейна, цифровых двойников, дополненной реальности, аддитивного производства, роботов и когнитивных технологий. Однако нужно сделать поправку, что такие технологии, как централизованные хранилища и центры обработки данных, широкополосный доступ в Интернет, которые пристально рассматриваются многими компаниями и экспертами, имеют незначительное влияние на развитие цифровизации экономики. Самая важная и определяющая технология цифровизации экономики - цифровая платформа. Являясь программным продуктом, она содержит в себе другие технологии, которые предоставляют пользователям доступ к информации, дают право на высококачественные сервисы, среди которых можно выделить планирование, аналитику и доступ к рынку (клиенты, производители, сервисные организации). Цифровизация экономики не развивалась бы так успешно в последние годы без качественного скачка в развитии информационно-коммуникационных технологий и четырех обстоятельств:

а) расширяется сфера применения цифровых технологий;

б) падает стоимость внедрения и эксплуатации цифровых инструментов;

в) цифровизация экономики стабильно растет;

г) растет доступ к цифровым устройствам (компьютеры, смартфоны, умные приборы и машины, подключенные к Интернету товаров) и их распространение.

За комплексом этих факторов стоит новая модель бизнеса, в которой развиваются цифровые экосистемы, основанные на цифровых платформах. У цифровых платформ, синтезирующих инструментарий цифровой экономики, есть новые технологии, возможность пользоваться цифровыми инструментами и свободным конкурентным рынком. Они создают единую информационную среду, которая приводит к снижению транзакционных издержек (применяются цифровые технологии и изменяется система разделения труда) [Кудряшов 2018].

По развитию своих свойств выделяются следующие цифровые платформы:

a) технологическая - предоставляет доступ к товарам, потребителям, ИТ-услугам (например, Alibaba Cloud);

б) функциональная - предоставляет доступ к специальным инструментам (например, 1C);

в) корпоративная - предоставляет доступ к оптимизации процессов управления (например, Госзакупки);

г) инфраструктурная - предоставляет доступ к цифровой инфраструктуре (например, Яндекс карты); 
е) маркетплейсы - предоставляет доступ к рынку, где стороны взаимодействуют (например, Amazon);

ж) отраслевая - предоставляет доступ к оптимизации взаимодействия участников (например, Smartcat).

з) информационная - предоставляет информационный доступ к рынку (например, Яндекс-Маркет).

Развитая цифровая платформа имеет следующие группы пользователей: а) оператор цифровой платформы, осуществляющий управление функционалом; б) поставщик, который предоставляет товары и услуги, предлагающиеся платформой; в) потребитель, покупающий товары и услуги; г) сервисный поставщик, который создает функциональный модуль; д) регулятор, контролирующий осуществление мониторинга [Беликова 2018].

У развитой цифровой платформы есть ось, на которой она строится, - экономический процесс, например, Uber осуществляет взаимодействие таксистов и пользователей такси; CarSharing - взаимодействие владельцев автомобилей и арендаторов; Airbnb - взаимодействие арендодателей и арендаторов жилья. Покупатели используют эти маркетплейсные платформы, выбирая оптимальные товары. Цифровые платформы также отличаются алгоритмизированностью; для них характерно ограничение функционала, фиксация и запоминание всех транзакций. Для экономических процессов, реализованных на платформах, характерны прозрачность и аналитичность. При ведущем инструменте перехода на цифровые платформы (платформизация) оцифровываются и становятся прозрачными все экономические процессы: происходит формирование многоуровневой цифровой модели экономики, в которой учитывается каждая транзакция [Krakovsky 2015].

Цифровые платформы являются базисом цифровизации экономики. Каждая цифровая платформа может выступать как сектор цифровой экономики. Число платформ увеличивается, а вместе с ними увеличивается число секторов цифровой экономики. Возникает конкуренция между цифровыми платформами по степени влияния на экономический рост. Конкуренция вызывает у каждой цифровой платформы мотивацию к развитию, обновлению и совершенствованию. Развитие цифровых маркетплейсов постепенно ведет к первенству электронной торговли. Электронная торговля экономит время и силы человека. Она позволяет человеку иметь больше свободного времени для досуга, туризма, физической культуры и спорта. Для электронной торговли важное значение имеет волатильность курса национальной валюты. Необходимо предпринимать меры, прежде всего цифрового характера, для формирования устойчивого курса национальной валюты. Также важное место занимают цифровые банковские услуги, поэтому для цифровизации экономики очень важно развитие цифровых финансовых технологий [Семячков 2018].

В современном мире создается благоприятная технологическая инфраструктура Интернета, финансовых институтов. Пандемия повлияла на экономическую обстановку начала нового десятилетия. Ей сопутствуют девальвация национальной валюты, снижение реальных доходов населения. Эти проблемы ограничивают развитие финансовой грамотности населения, повышают чувствительность людей к рискам, связанным с освоением новых виртуальных продуктов. К тому же с помощью прогноза можно выявить проблему будущего, связанную с интенсивной цифровизацией экономики. Масса профессий будет в дальнейшем не нужна - возникнет проблема с занятостью населения и необходимостью его переобучивания и переквалификации. Электронная торговля благодаря цифровым платформам станет практически единственной. Традиционная же торговля станет анахронизмом. 
Электронные гаджеты с Интернетом - смартфоны, ноутбуки - станут важнейшим предметом для работы. Многие люди будут работать, взаимодействуя с электронными гаджетами и Интернетом. Цифровизация экономики позволит экономить ресурсы, рабочее время. Производительность и эффективность труда будет интенсивно возрастать, что будет служить фактором экономического роста при цифровизации экономики. Для экономического роста также необходимо решить проблему занятости. При устойчивом экономическом росте можно обеспечить населению минимальный ежемесячный доход независимо от наличия работы. Неработающий человек будет получать минимальный ежемесячный доход, который позволит человеку комфортно жить. Цифровизация экономики объективно приводит к безработице части людей, и общество должно о них позаботиться [Давыденко 2018].

Рост и развитие цифровых платформ позволит цифровой экономике стать логичной, структурированной и аналитической. Цифровая экономика предполагает одновременное развитие с «зеленой экономикой». Все меньше будут использоваться природные ресурсы, приоритет будет за восстанавливаемыми источниками. Также существенно изменится структура сельского хозяйства и рацион питания человека. Цифровое общество постарается бороться с загрязнением окружающей среды и глобальным потеплением улучшать экологию.

Bыводы. Цифровизация экономики охватила страны мира и стала лидером инновационных технологий в экономике. В мире возникают многочисленные стартапы в области цифровизации экономики. США возглавляют процесс цифровизации экономики. Китай в недалеком будущем претендует на роль лидера в цифровизации экономики. Уже к 2030 г. Китай может обойти США по объему цифровой экономики и числу стартапов. Цифровизации экономики уделяется повышенное внимание в многочисленных научных публикациях. Пока нет единого понимания сущности цифровизации экономики. Поэтому исследователи раскрывают ее особенности и типологию, выявляют секторы цифровой экономики.

Развитие секторов цифровой экономики имеет связь с развитием сетевой готовности. Индекс сетевой готовности рассчитывается международными экономическими организациями. Еще одним важным фактором цифровизации является распространенность в обществе смартфонов. Чем больше смартфонов у людей в обществе, тем быстрее развиваются сектора цифровой экономики, онлайн-бизнес. Также большое значение имеет наличие качественной связи. Раньше это была прежде всего телефонная связь и наличие телефонных аппаратов. Сейчас связь формируется прежде всего посредством Интернета и социальных сетей в связи с наличием у абсолютного большинства смартфонов и ноутбуков. Их распространенность в стране играет огромную роль в развитии цифровой экономики. То есть, можно заключить, что размеры территории, доля молодежи в составе населения, распространенность Интернета, число и распространенность смартфонов и ноутбуков играют существенную роль в цифровизации экономики и экономическом росте.

При цифровизации экономики выделяют такие сектора, как облака, распределенные вычисления, большие данные и интернет-товары. Вторая по важности группа секторов состоит из блокчейна, цифровых двойников, дополненной реальности, аддитивного производства, роботов и когнитивных технологий. И самое важное значение имеют цифровые платформы, которые создают базис для цифровой экономики; от их развития зависит будущее цифровой экономики.

Стартапы в цифровой экономике занимают ведущее место. Инвестиции в 
стартапы придают им силу и мотивацию к развитию. Стартапы меняют общественный сектор цифровой экономики. Общественный сектор является тем препятствием, которое не позволяет полностью «оцифровать» мир и человека, не дает возможности возникновения глобальной власти искусственного разума над человеком и обществом. Технологии искусственного разума могут контролировать только общественный сектор, парламентарии [Долгих 2016]. Общественный сектор играет цементирующую роль в цифровой экономике. Его функциями являются информационная безопасность, борьба с загрязнением окружающей среды, загрязнением мира пластиковыми отходами. Именно его инициативы могут способствовать восстановлению природы, безопасности жизни человека и общества, развитию цифровизации экономики, экономическому росту и улучшению экологии.

\section{Список литературы}

Антонопулос А.М. 2018. Интернет денег (пер. с англ., под науч. ред. А. Власова). М.: Олимп-Бизнес. 192 с.

Беликова К.М. 2018. Цифровая интеллектуальная экономика. - Наука и образование. № 8(99). С. 82-85.

Борисюк Н.К. 2018. Механизм развития цифровой экономики в регионе: трактовка понятия. - Интеллект. Инновации. Инвестиции. № 7. С. 18-22.

Давыденко Е.А. 2018. Эволюция концепции цифрового государства. Российское предпринимательство. Т. 19. № 2. С. 457-472.

Долгих Ф.И. 2016. Пожертвования как источник финансирования политических партий. - Бизнес в законе. Экономико-юридический журнал. № 1. С. 98-103.

Дубов В.С. 2020. Показатели оценки развития цифровой экономики. - Наука и экономика. № 7(16). С. 44-52.

Кудряшов А.А. 2018. Инфраструктура цифровой экономики. - Актуальные вопросы современной экономики. № 5. С. 25-32.

Сагынбекова А.С. 2018. Цифровая экономика. - Теория. Практика. Инновации. № 4. С. 67-73.

Семячков К.А. 2018. Трансформация общественного сектора в условиях цифровой экономики. - Журнал экономической теории. № 3. С. 545-548.

Anderson C. 2006. The Long Tail: Why the Future of Business is Selling Less of More. N.Y.: Hyperion. 288 p.

Krakovsky M. 2015. The Middleman Economy: How Brokers, Agents, Dealers, and Everyday Matchmakers Create Value and Profit. N.Y.: Palgrave Macmillan. 240 p.

Vise D. 2008. Google Story. N.Y.: Pan Books. 252 p.

\section{SOCIAL CHANGES IN THE DIGITALIZATION OF THE ECONOMY}

\footnotetext{
Abstract. Social changes in the digitalization of the economy have a pronounced relevance. The economy is becoming digital and this acceleration is spurred by the pandemic. Social changes during the digitalization of the economy have a positive direction, which is due to various reasons. Innovation and startups play a special role, driving the digital economy. The digital economy is an example of environmental friendliness, optimality, rationality, saving intellectual, physical, labor and natural resources. At the same time, the digital economy also carries enormous risks, which include hacking, cybercrimes,
} 
cyber fraud and the uncontrolled development of artificial intelligence technologies. Lack of national and international control over the development and use of these technologies can endanger the existence of humanity.

Keywords: digital economy, information security, artificial intelligence, ecology, employment of the population

ЕРОХИНА Оксана Валерьевна - кандидат политических наук, доцент департамента политологии факультета социальных наук и массовых коммуникаций Финансового университета при Правительстве РФ (125993, Россия, г. Москва, ГСП-3, Ленинградский пр-кт, 49; o.v.erokhina@ gmail.com)

\title{
ЦИФРОВЫЕ ФОРМЫ ПОЛИТИЧЕСКОГО УЧАСТИЯ В РОССИИ (на примере платформы «Активный гражданин»)
}

\begin{abstract}
Аннотация. В ходе реализации федерального курса на развитие цифровой экономики инициативы, направленные на привлечение граждан к процессу принятия управленческих решений, получают политическую поддержку. В настоящее время наиболее продуктивно они развиваются на муниципальном уровне власти, за исключением Москвы как города федерального значения. Статья посвящена анализу опыта функционирования столичной платформы «Активный гражданин» как наиболее успешного краудсорсингового проекта в РФ и отвечает на вопросы об особенностях и перспективах развития цифровых форм политического участия в России.

Ключевые слова: политическое участие, краудсорсинг, соуправление, электронный референдум, развитие Москвы, «Активный гражданин»

Статья подготовлена по результатам исследований, выполненныхза счет бюджетныхсредств погосударственному заданию Финансовому университету при Правительстве РФ.
\end{abstract}

$\mathrm{O}$ пираясь на мировую практику, можно выделить несколько направлений развития цифровых форм политического участия: планирование (проведение общественных слушаний, дискуссий), привлечение общественности к разработке новых управленческих решений (краудсорсинг), сотрудничество между государством и обществом для оптимального распределения ресурсов (краудфандинг), сотрудничество для повышения эффективности государственных услуг (сервисы сбора и мониторинга общественных оценок, проведение опросов), сотрудничество в сфере местного управления [Перезолова 2018]. В России основным инициатором процесса вовлечения граждан в системные формы политического участия выступает государство, и это обстоятельство непосредственно влияет на результативность взаимодействия общественных и властных структур. Общество в сфере соуправления представлено достаточно широким спектром социальных групп, при этом уровень гражданского активизма коррелирует с индивидуальным целеполаганием каждого гражданина в сфере образования, социальной коммуникации, самореализации [Седова 2014].

Ограничения, связанные с распространением коронавируса, способствовали дальнейшему развитию электронных сервисов, обеспечивающих участие граждан в принятии решений на местном уровне. Так, в Москве сервис «Активный 